\title{
Mites as biological tags of their hosts
}

\author{
NADIA BRUYNDONCKX,*FRANÇOIS BIOLLAZ,* SYLVAIN DUBEY,† JÉRÔME GOUDET* and \\ PHILIPPE CHRISTE* \\ *Department of Ecology and Evolution, University of Lausanne, CH 1015 Lausanne, Switzerland, +School of Biological Sciences, \\ University of Sydney, Heydon-Laurence Bld, A08, Science Road, Sydney, NSW 2006, Australia
}

\begin{abstract}
Movements and spatial distribution of host populations are expected to shape the genetic structure of their parasite populations. Comparing the genetic patterns of both interacting species may improve our understanding of their evolutionary history. Moreover, genetic analyses of parasites with horizontal transmission may serve as indicators of historical events or current demographic processes that are not apparent in the genetic signature of their hosts. Here, we compared mitochondrial variation in populations of the ectoparasitic mite Spinturnix myoti with the genetic pattern of its host, the Maghrebian bat Myotis punicus in North Africa and in the islands of Corsica and Sardinia. Mite mitochondrial differentiation among populations was correlated with both host mitochondrial and nuclear differentiation, suggesting spatial co-differentiation of the lineages of the two interacting species. Therefore our results suggest that parasite dispersal is exclusively mediated by host movements, with open water between landmasses as a main barrier for host and parasite dispersal. Surprisingly the unique presence of a continental European mite lineage in Corsica was inconsistent with host phylogeographical history and strongly suggests the former presence of European mouse-eared bats on this island. Parasites may thus act as biological tags to reveal the presence of their now locally extinct host.
\end{abstract}

Keywords: Corsica, mtDNA, North Africa, population genetics, Sardinia, Spinturnicidae

Received 9 February 2010; revision received 21 April 2010; accepted 27 April 2010

\section{Introduction}

Comparative phylogeographical studies can expand our understanding of the ecology and evolutionary history of host and parasite populations (Nieberding \& Olivieri 2007). For parasites, hosts represent a patchy and dynamic resource that varies spatially and temporally. At the population level, demography, movements and distribution of hosts are the main factors determining genetic structure of parasite populations, especially for parasites without free-living stages or with low dispersal ability (Nadler 1995; Criscione et al. 2005; Huyse et al. 2005; Whiteman \& Parker 2005; Barrett et al. 2008; McCoy 2009; Biollaz et al. 2010). Although evidence for vertical transmission is difficult to ascertain (see e.g. Schwarz et al. 2008), vertically transmitted parasites are

Correspondence: Nadia Bruyndonckx, Fax: +41216924165;

E-mail: nadia.bruyndonckx@unil.ch assumed to best retain the genealogical history of their host (Rannala \& Michalakis 2003; Wirth et al. 2005). However, horizontally transmitted parasites can also provide information on ecological history of their hosts by revealing non-reproductive interactions (Criscione \& Blouin 2004; Whiteman et al. 2004). The population genetics of such parasites could serve as indicators of historical events or current demographic processes that are not apparent in the genetic signature of their hosts. For example, Reed et al. (2004) have used parasite genealogies to infer direct contact between modern and archaic humans.

The aims of this study were to assess the phylogeographic pattern of one parasite species, to investigate how constraints imposed by the host's spatial distribution influence parasite genetic structure and to evaluate whether parasites may be used as biological tags of their hosts. As a model system, we used the wing mite Spinturnix myoti parasitizing three closely related bat 
species in the Western Palearctic region: the Maghrebian bat, Myotis punicus, the greater and the lesser mouseeared bats, M. myotis and M. blythii. Bats are flying and nocturnal mammals with cryptic lifestyles and the survey of their parasites may give more insight into their ecology and evolutionary history. Spinturnicid mite are ectoparasites living exclusively on the wing membranes of their bat hosts (Deunff \& Beaucournu 1981). They are direct (no intermediate host), obligate (no free-living stage) and contact transmitted parasites that cannot survive separately from their host for more than a few hours (Giorgi et al. 2004). As these mites depend strictly on host body contact for dispersal, they are especially suitable for inferring the history and ecology of their hosts. Unlike in other mammal host-parasite systems, adult female bats are more heavily parasitized than males (Zahn \& Rupp 2004; Lucan 2006; Christe et al. 2007). Female bat aggregation within breeding colonies (facilitating vertical and horizontal transmission) combined with a decrease in immune defences during pregnancy may constitute optimal conditions for parasite reproduction (Christe et al. 2000). Indeed, several studies showed that Spinturnix synchronize their reproduction with that of their hosts, with an increase in both prevalence and intensity during the reproductive period (Christe et al. 2000; Lucan 2006; Lourenco \& Palmeirim 2007, 2008; Reckardt \& Kerth 2009). Prevalence and intensity are lower on individual bats during spring and autumn and their reproductive activity is greatly reduced during hibernation (Rudnick 1960; Deunff \& Beaucournu 1981; Lourenco \& Palmeirim 2007, 2008). The precise generation time of Spinturnix is still not known but much shorter than that of its host.
The prevalence of Spinturnix myoti reaches almost $100 \%$ during summer in the three bat species (Christe et al. 2000; pers. obs.). The average intensity on adult females is about 7, 10 and 15 mites for M. blythii, M. myotis and M. punicus respectively (M. myotis and M. blythii: Christe et al. 2000, 2003, 2007; M. punicus: this study, unpublished). According to Bruyndonckx et al. (2009a), different Spinturnix species are never found on the same individual bat. Moreover, phylogenetic reconstruction of bat hosts and wing mites showed evidence for cospeciation and suggested that their evolutionary history involved also failure to speciate events and host switches (Bruyndonckx et al. 2009a).

The Maghrebian bat is widespread over western North Africa and also occurs on three Mediterranean islands (i.e. Corsica, Sardinia and Malta: Castella et al. 2000; Topál \& Ruedi 2001; Biollaz et al. 2010). The greater and lesser mouse-eared bats are living in sympatry throughout Western Europe and the Near East (Arlettaz et al. 1997b; Ruedi et al. 2008) and have never been found in sympatry with the Maghrebian bat. Here we focused on the association between $S$. myoti and M. punicus and collected mites over most of the distribution range of the host (Fig. 1). A recent genetic survey showed that island colonization by the Maghrebian bats has certainly occurred in a stepping stone manner during the Pleistocene, with currently hardly any gene flow between Corsica, Sardinia and North Africa (Biollaz et al. 2010). In contrast, within landmasses both males and females seem to be strong dispersers, even if in North Africa females appeared to be more philopat-

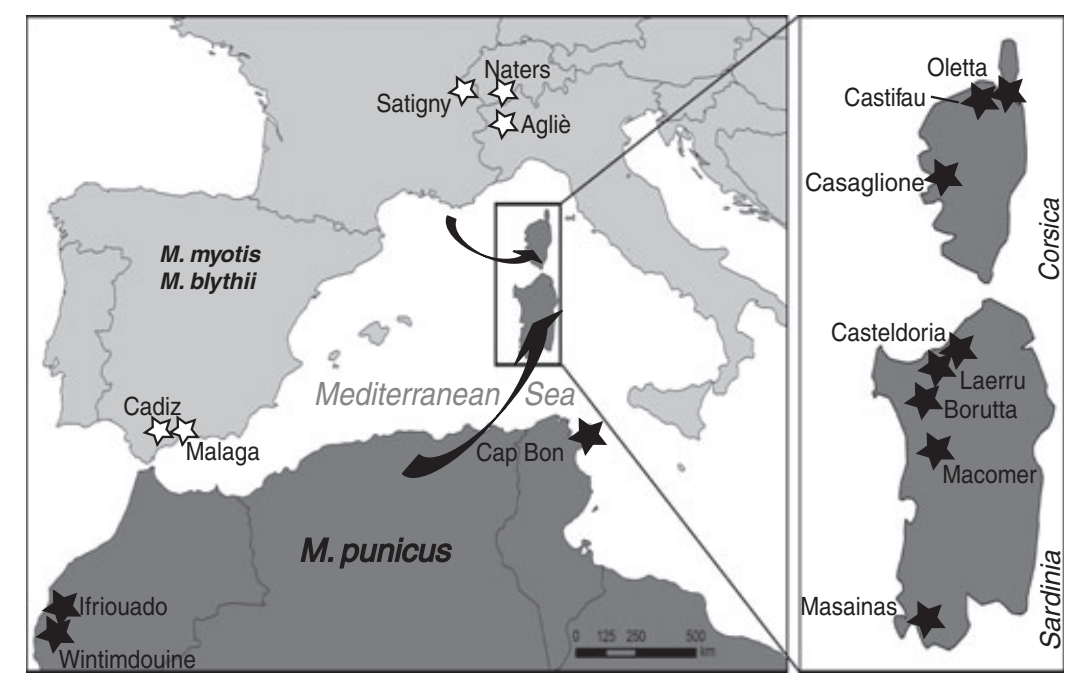

Fig. 1 Map of the studied area showing the 11 sampled populations of S. myoti on M. punicus (black stars) and five locations of additional mite samples from M. myotis and M. blythii (white stars). Distribution range of M. punicus is in dark grey and that of M. myotis and blythii in light grey. Arrows represent potential colonization routes of the islands of Corsica and Sardinia by the wing mite S. myoti. 
ric than males (Biollaz et al. 2010). Based on our knowledge of the host and the life style of the parasite, we expect mite genetic patterns to reflect that of its host i.e. more population differentiation between landmasses than within landmasses. Moreover, if mites followed their hosts in the colonization processes, we expect a lower genetic diversity in insular populations.

\section{Methods}

\section{Sampling}

In spring and summer 2006, we collected mites in 11 colonies of M. punicus in North Africa, Corsica and Sardinia covering most of the known distribution area of the host (Fig. 1). Most nursery colonies were composed of adult females and a few males living in natural caves or abandoned mines. To avoid disturbance during lactation, bats were caught before or at the end of the breeding season directly inside the nursery colonies during the day or mist-netted at the entrance of the cave at night. Animals were kept in separate textile bags to avoid contamination between individuals. Mites were collected with soft forceps from the bat wing membranes and preserved in ethanol $90 \%$ until processing. Five to seven mites per colony, each from a distinct bat, were used for the genetic analyses. As S. myoti is present on three host species, we added in the phylogenetic analysis some S. myoti samples of M. myotis and M. blythii from five colonies in Spain, Switzerland and Italy (Fig. 1).

\section{Mite DNA amplification and analyses}

DNA was extracted from each mite using a standard proteinase K-phenol chloroform method (Sambrook et al. 1989). We amplified and sequenced the 16S rRNA gene (16S) and the cytochrome oxydase subunit I (COI) as described in Bruyndonckx et al. (2009a). All products were analysed on an ABI Prism 3100 genetic analyzer (Applied Biosystems). Mite sequences were aligned and edited with Sequence NAvigator (Parker 1997).

We used ArLequin 3.1 (Excoffier et al. 2005) to assess the number of haplotypes $(N)$, haplotype diversity $(h)$ and nucleotide diversity $(\pi)$ within each population. Mean uncorrected genetic $p$-distances between colonies within and among landmasses (Corsica, Sardinia and North Africa) were calculated with Mega 3.1 (Kumar et al. 2004). We constructed the haplotype network using the method of statistical parsimony implemented in the software TCS 1.21 (Clement et al. 2000). Evolutionary relationships among all haplotypes of $S$. myoti populations were estimated by constructing phylogenetic trees using Bayesian and maximum-likelihood (ML) analyses. The Bayesian analysis was carried out using MrBayes 3.1
(Huelsenbeck et al. 2001), based on the most appropriate models of DNA substitution determined using MrModeltest 2.2 (Nylander 2004). This model (hLRT criterion) was a GTR + I + G (Rodriguez et al. 1990; Yang 1994). The Markov chain was run for 5000000 generations and sampled once every 1000 generations; burn-in was set to the first 1500 trees. To ensure convergence in the Bayesian analysis, two independent runs were performed. The ML analysis was performed with PhyML 3.0 software (Guindon \& Gascuel 2003), with the same parameters for the substitution model as suggested by MrModeltest 2.2. We generated bootstrap values based on 1000 resampled data sets. The trees were rooted using two specimens of a closely related species of the same genus, $S$. andegavinus (EU784873-EU784927 and EU784874-EU784928).

A hierarchical analysis of molecular variance (AMOvA) (Excoffier et al. 1992), inferred with ArLeQuin 3.1 (Excoffier et al. 2005), was used to estimate $\Phi$-statistics which incorporate information on nucleotide differences between haplotypes. Hence the proportions of variation among landmasses $\left(\Phi_{\text {landmass-total }}\right)$, between colonies within landmasses ( $\left.\Phi_{\text {colonies-landmass }}\right)$ and within colonies $\left(\Phi_{\text {individuals-colonies }}\right)$ were estimated. The significance of these $\Phi$-statistic values was assessed through randomizations using 10000 permutations. We calculated pairwise $\Phi$-statistics among all colonies with the same software. To test whether $\Phi$-statistics are sensitive to distances between haplotypes, we performed the same analyses based only on haplotypic frequencies.

We used BEAST v.1.4.8 (Drummond \& Rambaut 2007) to infer the time to the most recent common ancestor (TMRCA) of Sardinian populations. Because Corsican populations shared their unique haplotype with a Spanish population, it was not possible to infer the TMRCA of Corsican populations. We specified a relaxed clock with an uncorrelated lognormal distribution (Drummond et al. 2006) and a speciation Yule process as the tree prior. The rate of molecular evolution in Spinturnicid mites is unknown, as such we specified a prior distribution on evolutionary rate $(1.3 \pm 0.3 \% / \mathrm{Myr})$ on the basis of the pairwise $16 \mathrm{~S}$ and $\mathrm{CO}$ mutation rates of Arthropods (Brower 1994) and of the Orders Opiliones and Scorpiones (Gantenbein \& Largiader 2003; Thomas \& Hedin 2008; Ben Othmen et al. 2009). We performed two independent runs of 10000000 generations sampling every 1000 steps and removing $10 \%$ of the initial samples as burn-in. To control for convergence and to visualize the results, we used the program TRACER v.1.4 (Drummond \& Rambaut 2007).

\section{Host and parasite comparison}

Host mitochondrial and nuclear $F_{\mathrm{ST}}$ values were obtained from Biollaz et al. (2010), which included indi- 
vidual hosts of parasites sequenced in the present study. We calculated mite pairwise $F_{\mathrm{ST}}$ mito based on haplotypic frequencies only and tested the correlation between mite and host $F_{\mathrm{ST}}$ mito and between mite $F_{\mathrm{ST}}$ mito and host $F_{\mathrm{ST}}$ nucl, all measured as $F_{\mathrm{ST}} /\left(1-F_{\mathrm{ST}}\right)$. To determine if parasites were tracking host inter-colony gene flow, we used a Mantel test in Fstat 2.9.4 (Goudet 2002) to test the correlation between ectoparasite and host genetic distances. The colony of Masainas (Sardinia) was removed due to low host sample size.

\section{Results}

\section{Mite genetic analyses}

Among the 58 S. myoti associated with M. punicus sequenced, 21 different 16S/COI haplotypes were detected (one in Corsica, nine in Sardinia and 11 in North Africa, Table 1). The 963 aligned nucleotides consisted of 42 variable sites of which 32 were parsimonyinformative. $16 S$ and COI haplotypes were deposited in GenBank under accession numbers FJ225940-961 and FJ225883-904, respectively. A detailed list of the sampling localities, number of mites analysed per colony and mtDNA haplotypes per population are provided in Table 1.

The Bayesian and ML consensus trees (Fig. 2) revealed three well-supported clades corresponding to the same geographical groups defined by the haplotype network (Fig. 3). Unlike host phylogenetic pattern (Fig. 4), the first parasite clade covered Corsica and continental Europe with the same haplotype (c1) present all over Corsica and in Spain (Table 1, Figs. 2 and 3). The second clade comprised the North African populations and the last one the Sardinian populations (Figs. 2-4). We found no shared haplotypes between those three regions (Figs. 2 and 3). The uncorrected genetic $p$-distances were $1.5 \%$ between Corsica and Sardinia, 2.0\% between Corsica and North Africa and finally $2.5 \%$ between Sardinia and North Africa. The percentage of divergence within Corsica was null, $0.002 \%$ within Sardinia and $0.003 \%$ within North Africa. The haplotype number per population ranged from 1 to 6 (mean $=2.9$, Table 1$)$. Haplotype diversity ranged from 0.0 to 1.0 (mean $=0.587$, Table 1 ) and nucleotide diversity $(\%)$ from 0.0 to 0.402 (mean = 0.152 ; Table 1). Genetic diversity indices $(N, h, \pi)$ were higher in North African populations than in Sardinian populations, which in turn were higher than Corsican populations.

In agreement with the heterogeneity of haplotype distribution, the hierarchical AMOVA showed an important differentiation between landmasses $\left(\Phi_{\text {landmass-total }}=\right.$ 0.91, $P<0.001$; Table 2), whereas populations within landmasses where not significantly differentiated $\left(\Phi_{\text {colonies-landmass }}=0.10, P=0.072 ;\right.$ Table 2$)$. When

Table 1 Description of molecular variability of the 11 S. myoti populations associated with M. punicus sampled in this study and the five populations from continental Europe

\begin{tabular}{|c|c|c|c|c|c|c|c|c|}
\hline & Locality & Roost & Host species & $n$ & $N$ & $H$ & $\pi \%$ & Haplotype (no of individuals) \\
\hline \multirow[t]{4}{*}{ Corsica } & Castifau & Mine & M. punicus & 5 & 1 & 0.0 & 0 & $\mathbf{c 1}(5)$ \\
\hline & Oletta & Cave & M. punicus & 5 & 1 & 0.0 & 0 & $\mathbf{c 1}(5)$ \\
\hline & Casaglione & Building & M. punicus & 5 & 1 & 0.0 & 0 & c1(5) \\
\hline & & & & & 1 & 0.0 & 0 & \\
\hline \multirow[t]{6}{*}{ Sardinia } & Casteldoria & Mine & M. punicus & 5 & 3 & 0.7 & 0.229 & $\mathrm{~s} 1(1), \mathrm{s} 2(1), \mathrm{s} 3(3)$ \\
\hline & Borutta & Cave & M. punicus & 5 & 3 & 0.7 & 0.229 & s3(3), s4(1), s5(1) \\
\hline & Laerru & Cave & M. punicus & 5 & 3 & 0.8 & 0.229 & s3(2), s5(2), s6(1) \\
\hline & Macomer & Mine & M. punicus & 5 & 3 & 0.7 & 0.125 & s2(1), s5(3), s7(1) \\
\hline & Masainas & Cave & M. punicus & 5 & 3 & 0.7 & 0.145 & s5(3), s8(1), s9(1) \\
\hline & & & & & 3 & 0.7 & 0.191 & \\
\hline Tun. & Cap Bon & Cave & M. punicus & 6 & 6 & 1.0 & 0.402 & $\mathrm{t} 1(1), \mathrm{t} 2(1), \mathrm{tm} 3(1), \mathrm{t} 4(1), \mathrm{t} 5(1), \mathrm{t} 6(1)$ \\
\hline \multirow[t]{3}{*}{ Moro. } & Wintimdouine & Cave & M. punicus & 5 & 4 & 0.9 & 0.125 & $\mathrm{~m} 1(1), \mathrm{m} 2(1), \operatorname{tm} 3(2), \mathrm{m} 4(1)$ \\
\hline & Ifriouado & Cave & M. punicus & 7 & 4 & 0.9 & 0.188 & $\operatorname{tm} 3(2), \mathbf{m} 4(2), \operatorname{m5}(2), \mathrm{m} 6(1)$ \\
\hline & & & & & 4.7 & 0.9 & 0.238 & \\
\hline \multirow[t]{5}{*}{ Cont. Europe } & Cadiz & Cave & M. myotis & 4 & 4 & 1 & 0.277 & e1(1), e2(1), e3(1), e4(1) \\
\hline & Malaga & Cave & M. myotis & 4 & 3 & 0.8 & 0.156 & c1(2), e3(1), e5(1) \\
\hline & Aglié & Building & M. myotis & 3 & 3 & 1 & 0.277 & e6(1), e7(1), e8(1) \\
\hline & Naters & Attic & M. myoti/blythii & $2 / 4$ & 4 & 0.8 & 0.360 & e8(1), e9(1)/e9(2), e10(1), e11(1) \\
\hline & Satigny & Attic & M. myotis & 1 & & & & $\mathrm{e} 12(1)$ \\
\hline
\end{tabular}

The following parameters were estimated: number of individuals sequenced per colony $(n)$, total number of haplotypes $(N)$, haplotype diversity $(H)$, nucleotide diversity $(\pi)$ and distribution of haplotypes among populations. Numbers in bracket indicate the number of individuals per haplotype. Numbers in bold indicate haplotypes that are shared between two or more localities. 


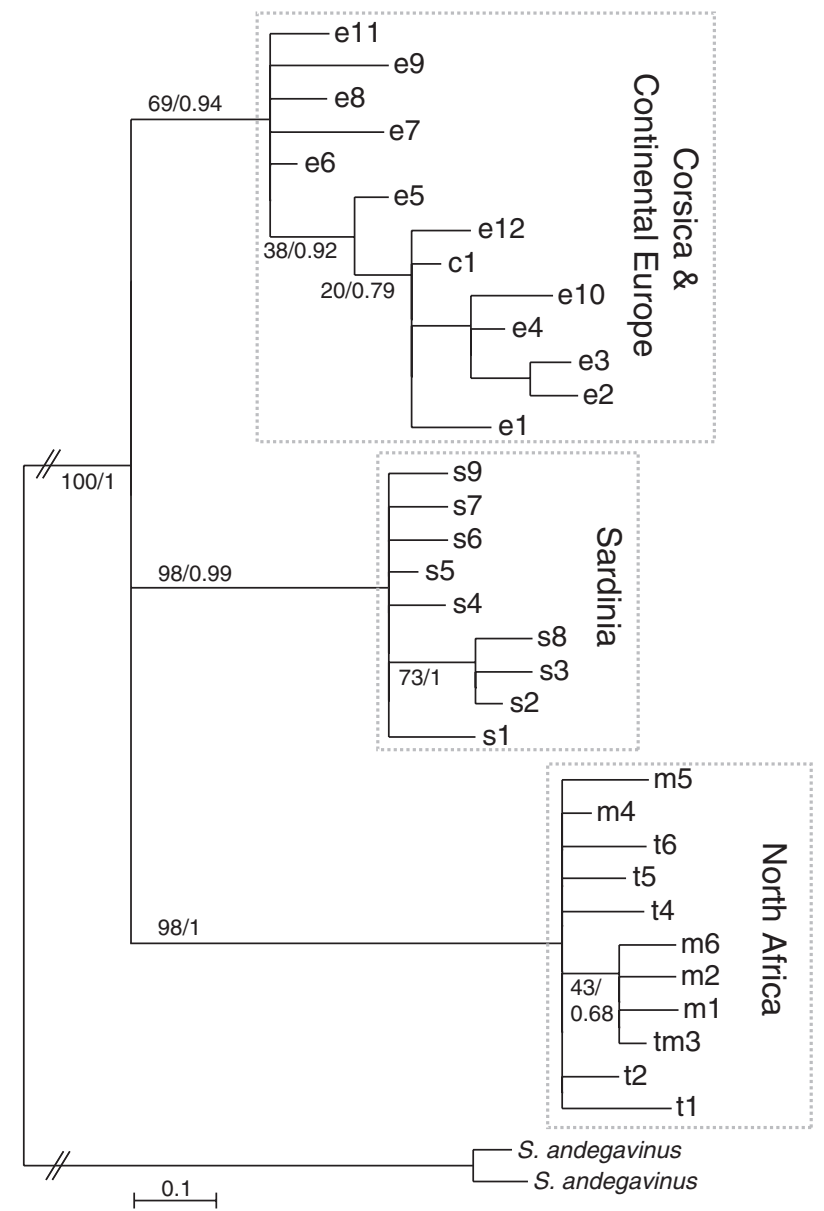

Fig. 2 Bayesian consensus tree representing the relationships between Corsican, Sardinian, Tunisian, Moroccan and continental European haplotypes of S. myoti, with maximum likelihood bootstrap values and Bayesian posterior probabilities. $S$. andegavinus is used as outgroup.

samples from continental Europe were included, populations between and within landmasses were significantly differentiated $\left(\Phi_{\text {landmass-total }}=0.86, P<0.001\right.$; $\Phi_{\text {colonies-landmass }}=0.19, P=0.002$; Table 2), reflecting the high diversity on continental Europe. Those patterns were confirmed by pairwise $\Phi_{\mathrm{ST}}$ values (Table 2): comparisons between pairs of colonies from different landmasses were all significant, except Corsican populations that were similar to a Spanish one (Malaga), while none were significant within landmasses, except the Sardinian most southern population (Masainas), which was slightly different from the most northern one (Casteldoria). Patterns of differentiation between colonies were similar but less marked when genetic distances were based only on haplotypic frequencies.

The result of the analysis with Beast suggested that the most recent common ancestor (TMRCA) of Sardinian populations dates back to the Mid Pleistocene (mean: 0.354Ma, 95\% HPD: 0.127-0.669Ma). This result

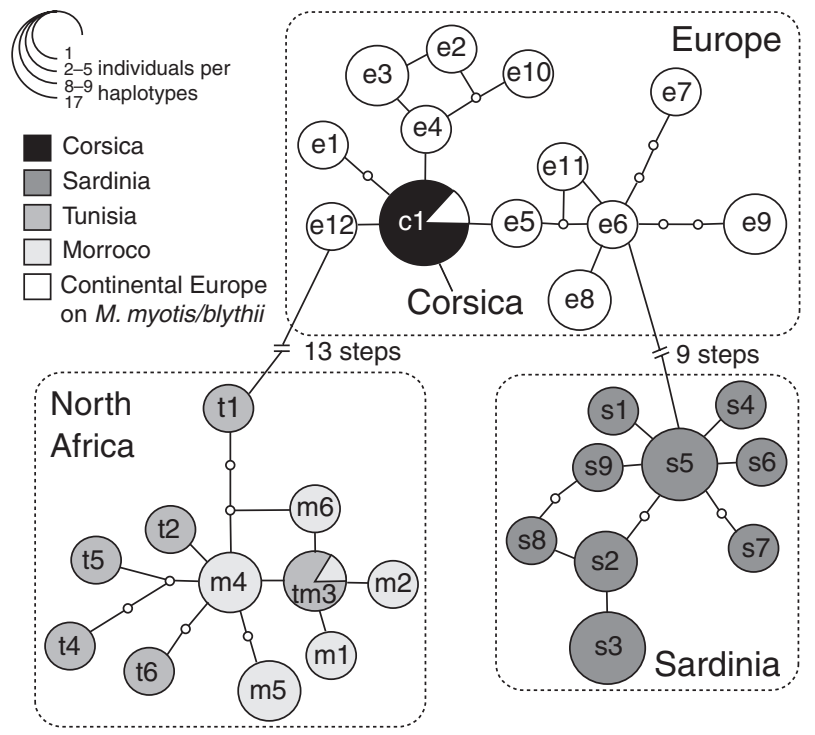

Fig. 3 Haplotype network based on 33 haplotypes of S. myoti evidenced by sequencing $16 S$ and COI mitochondrial genes of 76 mites from 11 colonies of M. punicus in North Africa, Sardinia and Corsica and five colonies of M. myotis/blythii in Spain, Switzerland and Italy. Numbers correspond to the mutational steps observed between clades and the size of the circle is proportional to the numbers of haplotypes represented.

is in accordance with that of its host, which was estimated to date back to the Early-Mid Pleistocene (Biollaz et al. 2010). However, this dating should be taken with cautious as regards no mutation rate of closely related parasitic mites is known.

\section{Host and parasite comparison}

We applied simple Mantel test analyses to examine the correlations among genetic distances of the host and the parasite. Mantel test analyses revealed that mite interpopulation $F_{\mathrm{ST}}$ mito values were highly correlated with their host genetic values. This correlation was more pronounced with host $F_{\mathrm{ST} \text { nuc }}$ than with host $F_{\mathrm{ST} \text { mito }}$ values ( $r=0.763, P<0.001 ; r=0.508, P=0.002$, respectively). This correlation mainly reflected the population distribution over the different landmasses, as revealed by a statistically non-significant correlation when landmasses are taken into account in the analysis.

\section{Discussion}

This study suggests that S. myoti and its host, the Maghrebian bat, share a common genetic and geographic structure. As expected, mite populations of Corsica, Sardinia and North Africa were highly differentiated with no shared haplotypes. Mite dispersal across water is currently totally hampered reflecting the bat genetic pattern (Biollaz et al. 2010). Moreover, mites seemed to 


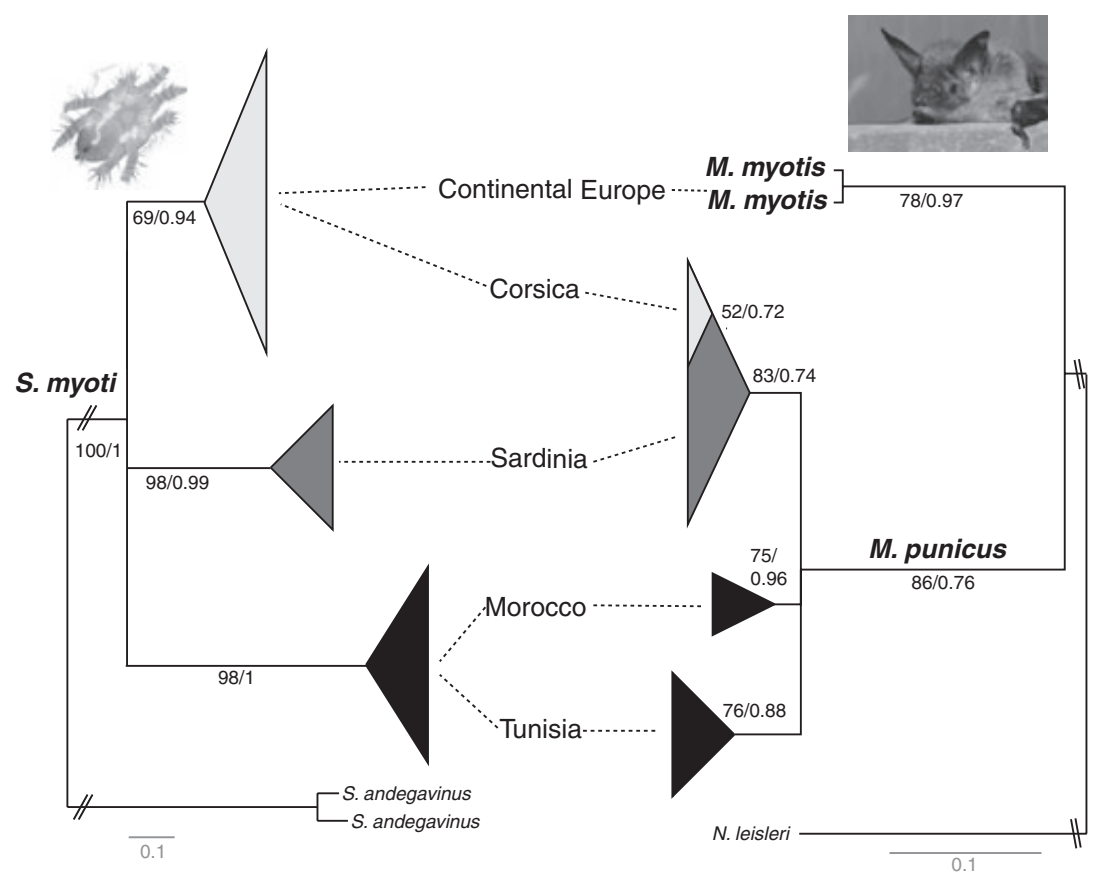

Fig. 4 Graphical display of parasite (left side) and host (right side) bayesian consensus trees. The links represent the association between host and parasite clades.

Table 2 Hierarchical AMOVA among (A) eleven populations of Spinturnix myoti partitioned by geographical landmasses (North Africa, Sardinia, Corsica), (B) including four populations from continental Europe. Asterisks indicate significant $P$ values

\begin{tabular}{|c|c|c|c|c|c|}
\hline $\begin{array}{l}\text { Source of } \\
\text { variation }\end{array}$ & $\mathrm{df}$ & $\begin{array}{l}\text { Sum of } \\
\text { squares }\end{array}$ & $\begin{array}{l}\text { Variance } \\
\text { components }\end{array}$ & $\begin{array}{l}\% \text { of } \\
\text { variation }\end{array}$ & $\Phi_{\mathrm{ST}}$ \\
\hline $\begin{array}{l}\text { (A) Among } \\
\text { landmasses }\end{array}$ & 2 & 337.1 & 8.86466 & 91.3 & $0.91^{* * *}$ \\
\hline $\begin{array}{l}\text { Among colonies } \\
\text { within landmasses }\end{array}$ & 8 & 9.5 & 0.08105 & 0.83 & 0.10 \\
\hline Within colonies & 47 & 35.9 & 0.76373 & 7.87 & \\
\hline Total & 57 & 382.5 & 9.70943 & & \\
\hline $\begin{array}{l}\text { (B) Among } \\
\text { landmasses }\end{array}$ & 3 & 388.4 & 6.89100 & 86.2 & $0.86^{* * *}$ \\
\hline $\begin{array}{l}\text { Among colonies } \\
\text { within landmasses }\end{array}$ & 11 & 21.3 & 0.21208 & 2.65 & $0.19^{* *}$ \\
\hline Within colonies & 60 & 53.5 & 0.89131 & 11.15 & \\
\hline Total & 74 & 463.2 & 7.99439 & & \\
\hline
\end{tabular}

have followed their bat hosts in the island colonization process and colonized the island of Sardinia during the Pleistocene. However, one notable exception, decreasing the similarity between host and parasite patterns, is the colonization of the island of Corsica: Corsican parasites originate from continental Europe whereas their hosts have a North African origin.

Maghrebian bats from Corsica, despite their close phylogenetic relationship with those of Sardinia (Biollaz et al. 2010), harbour mites genetically similar to those infesting M. myotis/blythii from continental Europe. As mites cannot survive more than a couple of hours without their host (Giorgi et al. 2004), the presence of this continental European mite lineage on the island of Corsica is best explained by a direct switch from M. myotis/blythii to M. punicus. However, M. punicus currently does not occur in sympatry with $M$. myotis nor with $M$. blythii. The best explanation to elucidate the presence of continental European mites on Corsican bats is therefore the occurrence of mouse-eared bats on Corsica once in the past. Competitive exclusion may explain the nowadays unique presence of Maghrebian bats in Corsica, as its ecological niche is similar to that of mouseeared bats (Arlettaz et al. 1997a; b; Castella et al. 2000).

The presence of one unique mite haplotype in Corsica might result from two successive bottlenecks: the first one when mouse-eared bats colonized Corsica from continental Europe, potentially during the Pleistocene variation of the sea level and the second one during our hypothesized host switch between the mouse-eared bat and Maghrebian bat when they co-occurred in Corsica. Competitive exclusion may also explain the nowadays absence of Sardinian mite lineages in Corsica. Only experimental survival tests of different parasite lineages in competition on the same host might permit to test this hypothesis.

The time of the most common ancestor of the Sardinian populations of S. myoti was estimated to date back 
Table 3 Estimates of $\Phi_{\mathrm{ST}}$ between 15 populations of S. myoti

\begin{tabular}{|c|c|c|c|c|c|c|c|c|c|c|c|c|c|c|c|}
\hline & & Cast. & Olet. & Casagl. & Castel. & Boru. & Laer. & Mac. & Mas. & Cap. & Wint. & Ifr. & Cadiz & Mala. & Naters \\
\hline \multirow[t]{3}{*}{ Corsica } & Castifau & & & & & & & & & & & & & & \\
\hline & Oletta & 0 & & & & & & & & & & & & & \\
\hline & Casaglione & 0 & 0 & & & & & & & & & & & & \\
\hline \multirow[t]{5}{*}{ Sardinia } & Casteldoria & $0.92^{* *}$ & $0.92^{* *}$ & $0.92^{* *}$ & & & & & & & & & & & \\
\hline & Borutta & $0.92^{* *}$ & $0.92^{* *}$ & $0.92^{* *}$ & -0.12 & & & & & & & & & & \\
\hline & Laerru & $0.92^{* *}$ & $0.92^{* *}$ & $0.92^{* *}$ & 0.02 & -0.12 & & & & & & & & & \\
\hline & Macomer & $0.95^{* *}$ & $0.95^{* *}$ & $0.95^{* *}$ & 0.34 & 0.2 & -0.01 & & & & & & & & \\
\hline & Masainas & $0.95^{* *}$ & $0.95^{* *}$ & $0.95^{* *}$ & $0.35^{*}$ & 0.22 & 0.04 & -0.05 & & & & & & & \\
\hline Tun. & Cap Bon & $0.88^{* *}$ & $0.88^{* *}$ & $0.88^{* *}$ & $0.87^{* *}$ & $0.87^{* *}$ & $0.87^{* *}$ & $0.88^{* *}$ & $0.88^{* *}$ & & & & & & \\
\hline \multirow[t]{2}{*}{ Morocco } & Wintimdouine & $0.97^{* *}$ & $0.97^{* *}$ & $0.97^{* *}$ & $0.93^{* *}$ & $0.93^{* *}$ & $0.93^{* *}$ & $0.95^{* *}$ & $0.94^{* *}$ & 0.12 & & & & & \\
\hline & Ifriouado & $0.94^{* *}$ & $0.94^{* *}$ & $0.94^{* *}$ & $0.92^{* *}$ & $0.92^{* *}$ & $0.92^{* *}$ & $0.93^{* *}$ & $0.93^{* *}$ & 0.05 & 0.08 & & & & \\
\hline \multirow[t]{4}{*}{ Cont. Europe } & Cadiz & $0.40^{* *}$ & $0.40^{* *}$ & $0.40^{* *}$ & $0.86^{* *}$ & $0.85^{* *}$ & $0.84^{* *}$ & $0.87^{* *}$ & $0.87^{* *}$ & $0.82 * *$ & $0.90^{* *}$ & $0.89^{*}$ & & & \\
\hline & Malaga & 0.06 & 0.06 & 0.06 & $0.87^{* *}$ & $0.87^{* *}$ & $0.86^{* *}$ & $0.90^{* *}$ & $0.89^{* *}$ & $0.84^{* *}$ & $0.93^{* *}$ & $0.91^{* *}$ & 0.02 & & \\
\hline & Naters & $0.53^{* *}$ & $0.53^{* *}$ & $0.53^{* *}$ & $0.83^{* *}$ & $0.82^{* *}$ & $0.82^{* *}$ & $0.84^{* *}$ & $0.83^{* *}$ & $0.80^{* *}$ & $0.86^{* *}$ & $0.86^{*}$ & $0.40^{*}$ & $0.38^{*}$ & \\
\hline & Agliè & $0.71^{*}$ & $0.71^{*}$ & $0.71^{*}$ & $0.84^{*}$ & $0.83^{*}$ & $0.83^{*}$ & $0.87^{*}$ & $0.86^{*}$ & $0.82^{*}$ & $0.91^{*}$ & $0.90^{*}$ & $0.39^{*}$ & $0.41^{*}$ & 0.09 \\
\hline
\end{tabular}

${ }^{*} P<0.05,{ }^{* *} P<0.01$ and ${ }^{* * *} P<0.001$; Populations are abbreviated as followed: Cast.: Castifau; Olet.: Oletta; Casagl.: Casaglione; Castel.: Casteldoria; Boru.: Borutta; Laer.: Laerru; Mac.: Macomer; Mas.: Masainas; Cap.: Cap Bon; Wint.: Wintimdouine; Ifr.: Ifriouado; Mala.: Malaga. Tun.: Tunisia.

to the Mid Pleistocene, suggesting that mites have followed the Maghrebian bat in Sardinia. Indeed, Biollaz et al. (2010) showed that Sardinia and Corsica colonization by the Maghrebian bat might have occurred in a stepping stone manner during the Pleistocene. The emergence of land bridges due to the low sea level during the successive glacial periods favoured first the colonization of Sardinia and then the colonization of Corsica from Sardinia. The expected and observed lower haplotype and nucleotide diversity in Sardinian mites compared to North African mainland may thus results from a strong bottleneck during the colonization events (Frankham 1996). This 'island syndrome' has been poorly investigated in parasite species but has been reported in the nematode Heligmosomoides polygyrus infesting Apodemus sylvaticus and Mus musculus (Nieberding et al. 2006). Finally, the presence of the same mite haplotype in Corsica and Spain prevents the dating of the most common ancestor of Corsican populations.

Alternative hypotheses to explain the presence of a continental European mite lineage in Corsica would require the presence of the parasite $S$. myoti on other bat species inhabiting Corsica. This latter scenario would imply two host-switches and seems unlikely since we found that co-roosting bat species harboured their own specific Spinturnix species (more than $10 \%$ of divergence) in Corsica (Bruyndonckx et al. 2009a). A very recent colonization from the mainland seems also unlikely since the minimal distance between Corsica and Italy is approximately $80 \mathrm{~km}$, a distance much larger than the strait of Bonifacio $(12 \mathrm{~km})$ that has been shown to represent a strong barrier to gene flow between Corsica and Sardinia for the Maghrebian bats
(Biollaz et al. 2010). Other alternatives would require improbable scenarios of colonization, recolonization and extinction in Europe and Corsica.

Spinturnix myoti exhibited an important and significant population genetic structure between Corsica, Sardinia and North Africa, while within those three regions populations were not genetically differentiated. This latter result is consistent with a very high gene flow among mite populations within landmasses, a pattern that differs from the genetic structure of bats in North Africa (Biollaz et al. 2010). Indeed, the Maghrebian bats showed a male-biased dispersal, with females being highly philopatric, resulting in a high mitochondrial differentiation between Tunisian and Moroccan colonies (Biollaz et al. 2010). Mite dispersal among remote colonies may occur via males and females during mating where territorial males may form loose lecks (Horácek \& Gaisler 1986). Parasite transmission during mating has been recently suggested to strongly influence population genetics in the mite S. bechsteini infesting the Bechstein's bat (Myotis bechsteinii) (Bruyndonckx et al. 2009b). Moreover, in North Africa, bats have been reported to hibernate from time to time in small clusters which could give opportunities for mite dispersal (Kowalski et al. 1986). A detailed picture of mite movements can be revealed in the future through the use of microsatellite markers which development is currently in progress. Other studies on the importance of host movements on the genetic structure of parasite populations have been previously documented, for example in nematodes of Ungulates (Blouin et al. 1995), in trematodes that infect salmonid fishes (Criscione \& Blouin 2004) and in seabird ticks (McCoy et al. 2003). 
In addition to their use in detecting cryptic species (Criscione \& Blouin 2004), refuges during glaciations (Nieberding et al. 2004; Toon \& Hughes 2008), former contacts (Reed et al. 2004) and demography (Biek et al. 2006) of their hosts, we show that a parasite with both vertical and horizontal transmission might also reveal the past co-occurrence and contact of different host species that allowed the exchange of parasite lineages. The past distribution of presently extinct populations of host plants was similarly highlighted by the genetic pattern of its symbiont (Anderson et al. 2004). In conclusion, the population structure of $S$. myoti is highly dependent on host movements. This contact transmitted parasite appears to be a good proxy to detect the former presence of a nowadays locally extinct host species, i.e. mouseeared bats in Corsica, that would have been virtually impossible to reveal without good fossil evidence.

\section{Acknowledgements}

We are grateful to many people who assisted with the collection of specimens especially G. Beuneux (Groupe Chiroptères Corse), C. Ibáñes, J. Quetglas, A. Popa-Lisseanu, J. Juste (Estación Biológica de Doñana, Sevilla), J. Ramon and Olvido (Malaga), M. Muccedda (Sardinia), Chef de la brigade de chasse de Nabeul (Tunisia), L. Faouzi, A. Ighous (Morocco), E. Patriarca, P. Debernardi (Italy), R. Arlettaz, P. Roduit (Suisse). Thanks to G. Devevey, G. Emaresi, P. Fontanillas, A. Horn, Ana PopaLisseanu, L. Keller, 3 anonymous referees and F. Balloux for useful comments on the manuscript and F. Witsenburg for the English revision of the manuscript. This work is supported by the Swiss National Science Foundation 31003A_120479.

\section{References}

Anderson B, Olivieri I, Lourmas M, Stewart BA (2004) Comparative population genetic structures and local adaptation of two mutualists. Evolution, 58, 1730-1747.

Arlettaz R, Perrin N, Hausser J (1997a) Trophic resource partitioning and competition between the two sibling bat species Myotis myotis and Myotis blythii. Journal of Animal Ecology, 66, 897-911.

Arlettaz R, Ruedi M, Ibáñez C, Palmeirim J, Hausser J (1997b) A new perspective on the zoogeography of the sibling mouse-eared bat species Myotis myotis and Myotis blythii: morphological, genetical and ecological evidence. Journal of Zoology (London), 242, 45-62.

Barrett LG, Thrall PH, Burdon JJ, Linde CC (2008) Life history determines genetic structure and evolutionary potential of host-parasite interactions. Trends in Ecology and Evolution, 23, 678-685.

Ben Othmen A, Said K, Mahamdallie SS et al. (2009) Phylogeography of Androctonus species (Scorpiones: Buthidae) in Tunisia: Diagnostic characters for linking species to scorpionism. Acta Tropica, 112, 77-85.

Biek R, Drummond AJ, Poss M (2006) A virus reveals population structure and recent demographic history of its carnivore host. Science, 311, 538-541.
Biollaz F, Bruyndonckx N, Beuneux G et al. (2010) Genetic isolation of insular populations of the Maghrebian bat Myotis punicus in the Mediterranean Basin. Journal of Biogeography, DOI: $10.1111 /$ j.1365-2699.2010.02282.x.

Blouin MS, Yowell CA, Courtney CH, Dame JB (1995) Host movement and the genetic-structure of populations of parasitic nematodes. Genetics, 141, 1007-1014.

Brower AVZ (1994) Rapid morphological radiation and convergence among races of the butterfly Heliconius erato inferred from patterns of mitochondrial-DNA evolution. Proceedings of the National Academy of Sciences, USA, 91, 64916495.

Bruyndonckx N, Dubey S, Ruedi M, Christe P (2009a) Molecular cophylogenetic relationships between European bats and their ectoparasitic mites (Acari, Spinturnicidae). Molecular Phylogenetics and Evolution, 51, 227-237.

Bruyndonckx N, Henry I, Christe P, Kerth G (2009b) Spatiotemporal population genetic structure of the parasitic mite Spinturnix bechsteini is shaped by its own demography and the social system of its bat host. Molecular Ecology, 18, 3581-3592.

Castella V, Ruedi M, Excoffier L et al. (2000) Is the Gibraltar Strait a barrier to gene flow for the bat Myotis myotis (Chiroptera: Vespertilionidae)? Molecular Ecology, 9, 1761-1772.

Christe P, Arlettaz R, Vogel P (2000) Variation in intensity of a parasitic mite (Spinturnix myoti) in relation to the reproductive cycle and immunocompetence of its bat host (Myotis myotis). Ecology Letters, 3, 207-212.

Christe P, Giorgi MS, Vogel P, Arlettaz R (2003) Differential species-specific ectoparasitic mite intensities in two intimately coexisting sibling bat species: resource- mediated host attractiveness or parasite specialization? Journal of Animal Ecology, 72, 866-872.

Christe P, Glaizot O, Evanno G et al. (2007) Host sex and ectoparasites choice: preference for, and higher survival on female hosts. Journal of Animal Ecology, 76, 703-710.

Clement M, Posada D, Crandall KA (2000) TCS: a computer program to estimate gene genealogies. Molecular Ecology, 9, $1657-1659$.

Criscione CD, Blouin MS (2004) Life cycles shape parasite evolution: comparative population genetics of salmon trematodes. Evolution, 58, 198-202.

Criscione CD, Poulin R, Blouin MS (2005) Molecular ecology of parasites: elucidating ecological and microevolutionary processes. Molecular Ecology, 14, 2247-2257.

Deunff J, Beaucournu J-C (1981) Phénologie et variations du dermecos chez quelques espèces de Spinturnicidae (Acarina, Mesostigmata). Annales de Parasitologie Humaine et Comparée, 56, 203-244.

Drummond AJ, Rambaut A (2007) BEAST: Bayesian evolutionary analysis by sampling trees. BMC Evolutionary Biology, 7, 214.

Drummond AJ, Ho SYW, Phillips MJ, Rambaut A (2006) Relaxed phylogenetics and dating with confidence. PLoS Biology, 4, 699-710.

Excoffier L, Smouse PE, Quattro JM (1992) Analysis of molecular variance inferred from metric distances among DNA haplotypes-application to human mitochondrial-DNA restriction data. Genetics, 131, 479-491.

Excoffier L, Laval G, Schneider S (2005) Arlequin ver. 3.0: An integrated software package for population genetics data analysis. Evolutionary Bioinformatics Online, 1, 47-50. 
Gantenbein B, Largiader CR (2003) The phylogeographic importance of the Strait of Gibraltar as a gene flow barrier in terrestrial arthropods: a case study with the scorpion Buthus occitanus as model organism. Molecular Phylogenetics and Evolution, 28, 119-130.

Giorgi MS, Arlettaz R, Guillaume F et al. (2004) Causal mechanisms underlying host specificity in bat ectoparasites. Oecologia, 138, 648-654.

Goudet J (2002) FSTAT 2.9.3.2, A Program to Estimate and Test Gene Diversities and Fixation Indices (updated from Goudet 1995). Lausanne, Switzerland, Available at: http:// www2.unil.ch/popgen/softwares/fstat.htm.

Guindon S, Gascuel O (2003) A simple, fast, and accurate algorithm to estimate large phylogenies by maximum likelihood. Systematic Biology, 52, 696-704.

Horácek I, Gaisler J (1986) The mating system of Myotis blythi. Myotis, 23-24, 125-129.

Huelsenbeck JP, Ronquist F, Nielsen R, Bollback JP (2001) Evolution-Bayesian inference of phylogeny and its impact on evolutionary biology. Science, 294, 2310-2314.

Huyse T, Poulin R, Theron A (2005) Speciation in parasites: a population genetics approach. Trends in Parasitology, 21, 469475

Kowalski K, Gaisler J, Bessam H, Issaad C, Ksantini H (1986) Annual life-cycle of cave bats in Northern Algeria. Acta Theriologica, 31, 185-206.

Kumar S, Tamura K, Nei M (2004) MEGA3: integrated software for molecular evolutionary genetics analysis and sequence alignment. Briefings in Bioinformatics, 5, 150-163.

Lourenco SI, Palmeirim JM (2007) Can mite parasitism affect the condition of bat hosts? Implications for the social structure of colonial bats. Journal of Zoology (London), 273, $161-168$.

Lourenco S, Palmeirim JM (2008) Which factors regulate the reproduction of ectoparasites of temperate-zone cavedwelling bats? Parasitology Research, 104, 127-134.

Lucan RK (2006) Relationships between the parasitic mite Spinturnix andegavinus (Acari: Spinturnicidae) and its bat host, Myotis daubentonii (Chiroptera: Vespertilionidae): seasonal, sex- and age-related variation in infestation and possible impact of the parasite on the host condition and roosting behaviour. Folia Parasitologica (Ceske Budejovice), 53, 147-152.

McCoy KD (2009) Host-parasite determinants of parasite population structure: lessons from bats and mites on the importance of time. Molecular Ecology, 18, 3545-3547.

McCoy KD, Boulinier T, Tirard C, Michalakis Y (2003) Hostdependent genetic structure of parasite populations: differential dispersal of seabird tick host races. Evolution, 57, 288-296.

Nadler SA (1995) Microevolution and the genetic-structure of parasite populations. Journal of Parasitology, 81, 395-403.

Nieberding CM, Olivieri I (2007) Parasites: proxies for host genealogy and ecology? Trends in Ecology and Evolution, 22, 156-165.

Nieberding C, Morand S, Libois R, Michaux JR (2004) A parasite reveals cryptic phylogeographic history of its host. Proceedings of the Royal Society of London Series B: Biological Sciences, 271, 2559-2568.

Nieberding C, Morand S, Libois R, Michaux JR (2006) Parasites and the island syndrome: the colonization of the western
Mediterranean islands by Heligmosomoides polygyrus (Dujardin, 1845). Journal of Biogeography, 33, 1212-1222.

Nylander JAA (2004) MrModeltest 2.2. Department of Systematic Zoology, Evolutionary Biology Centre, Uppsala University, Sweden.

Parker SR (1997) Sequence Navigator. Multiple sequence alignment software. Methods in Molecular Biology, 70, 145-154.

Rannala B, Michalakis Y (2003) Population genetics and cospeciation: from process to pattern. In: Tangled Trees: Phylogeny, Cospeciation and Coevolution (ed. Page RDM), pp. 120-143. The University of Chicago Press, Chicago.

Reckardt K, Kerth G (2009) Does the mode of transmission between hosts affect the host choice strategies of parasites? Implications from a field study on bat fly and wing mite infestation of Bechstein's bats. Oikos, 118, 183-190.

Reed DL, Smith VS, Hammond SL, Rogers AR, Clayton DH (2004) Genetic analysis of lice supports direct contact between modern and archaic humans. PLoS Biology, 2, 1972 1983.

Rodriguez F, Oliver JL, Marin A, Medina JR (1990) The general stochastic-model of nucleotide substitution. Journal of Theoretical Biology, 142, 485-501.

Rudnick A (1960) A revision of the mites of the family Spinturnicidae. University of California Press, 17, 157-284.

Ruedi M, Walter S, Fischer MC et al. (2008) Italy as a major ice age refuge area for the bat Myotis myotis (Chiroptera: Vespertilionidae) in Europe. Molecular Ecology, 17, 1801-1814.

Sambrook JE, Fritsch F, Manitatis T (1989) Molecular Cloning: A Laboratory Manual, 2nd edn. Cold Spring Harbor Laboratory Press, New York.

Schwarz S, Morelli G, Kusecek B et al. (2008) Horizontal versus familial transmission of Helicobacter pylori. Plos Pathogens, 4, e1000 180.

Thomas SM, Hedin M (2008) Multigenic phylogeographic divergence in the paleoendemic southern Appalachian opilionid Fumontana deprehendor Shear (Opiliones, Laniatores, Triaenonychidae). Molecular Phylogenetics and Evolution, 46, 645-658.

Toon A, Hughes J (2008) Are lice good proxies for host history? A comparative analysis of the Australian magpie, Gymnorhina tibicen, and two species of feather louse. Heredity, 101, 127-135.

Topál G, Ruedi M (2001) Myotis blythii (Tomes, 1857)—Kleines Mausohr. In: Handbuch der Säugetiere Europas Bd 4/I (Fledertiere) (ed. Krapp F), pp. 209-255. AULA-Verlag GmbH, Wiebelsheim, Germany.

Whiteman NK, Parker PG (2005) Using parasites to infer host population history: a new rationale for parasite conservation. Animal Conservation, 8, 175-181.

Whiteman NK, Santiago-Alarcon D, Johnson KP, Parker PG (2004) Differences in straggling rates between two genera of dove lice (Insecta: Phthiraptera) reinforce population genetic and cophylogenetic patterns. International Journal for Parasitology, 34, 1113-1119.

Wirth T, Meyer A, Achtman M (2005) Deciphering host migrations and origins by means of their microbes. Molecular Ecology, 14, 3289-3306.

Yang Z (1994) Estimating the pattern of nucleotide substitution. Journal of Molecular Evolution, 39, 105-111.

Zahn A, Rupp D (2004) Ectoparasite load in European vespertilionid bats. Journal of Zoology (London), 262, 383-391. 